pathology for years to come.

The Atlas and Manual of Plant Pathology is, by comparison, not a work of any outstanding interest. A republication of a 1968 edition, with minor modifications, it treats a series of diseases on a taxonomic basis, giving general information on each (causal organism, symptoms, control), together with black and white photographs at macroscopic, hand-lens and microscopic levels. The descriptions are sometimes supplemented by details of laboratory experiments, which are possibly the most interesting part of the work and have not especially dated since the first edition. However, epidemiology receives little attention. The numerous photographs are certainly useful for the systematic study of plant diseases, However, with a certain prejudice against prepared slides, the present reviewer regrets the non-inclusion of any instructions on how to examine fresh or cleared material. At the other end of the scale, a modern text should surely show some of the insights given by electron microscopy.

The text is also regrettably out of date, and indeed misleading in many respects. Nomenclature is sometimes outdated and recent developments bypassed (crown gall). Most unfortunate perhaps is the very old-fashioned section on plant virology. The point is that, in this and many other respects, plant pathologists can be quite proud of the progress made in the last decade. It is a pity, therefore, to republish an old textbook, without taking the trouble to revise it.

I.M. Smith is Deputy Director-General of the European and Mediterranean Plant Protection Organization, Paris, France.

\section{Plant breeding}

\section{Barbara Pickersgill}

Principles of Crop Improvement. By N.W. Simmonds. Pp.408. (Longman: Harlow, UK, 1979.) £7.95.

THIS is the first new textbook on plant breeding for about 12 years, but a decade is a short time to a breeder so the subject matter discussed remains basically unaltered. Where this book differs from its predecessors is in its excellent treatment of conservation of genetic resources and the green revolution and, more particularly, in its uncompromisingly practical orientation.

Background information on crop evolution, population genetics, polygenic inheritance and heritability is used to discuss the breeder's very real problems of breeding strategy, selection, scale of operations and profitability in either social or real terms. Academically elegant special cases such as aneuploidy in barley or regulation of recombination in wheat breeding get little mention. Indeed, cytology takes a back seat throughout. Tropical crops provide about as many examples as temperate crops, which should increase this textbook's appeal to those teaching in developing countries.

Professor Simmonds writes clearly and concisely but two stylistic traits detract slightly from the book's readability. One is the intentional use of very long captions to tables or figures. By the time one has assimilated those, one tends to have lost the drift of the textual exposition the table or figure was to illustrate. The other is the use of abbreviations. Sentences such as "Thus, summarising the slightly confusing nomenclature of OPP breeding, we have: PIM (varieties propagable as such) contrasted with SYN (varieties regularly reconstructed from parents), with the former based on either MSL or PRT" may completely baffle students who find even basic genetic terminology difficult. Unfortunately there is no glossary, nor are abbreviations listed as such in the index.

Numerous thought-provoking examples for the reader to work are embedded in the text or captions and carry the textual argument further. It is therefore advisable to do one's homework thoroughly before assigning class reading in this book.

\section{The natural selection}

\section{M.J. Lawrence}

Introduction to Evolution. By F.A. Racle. Pp.161. (Prentice-Hall International: Hemel Hempstead, UK, 1979.) £5.80. The Biological Environment. Edited by J. Lenihan and W.W. Fletcher. Pp.164. (Blackie: Glasgow and London, 1979.) Hardback £9.95; paperback £4.95. Evolution. By C. Patterson. Pp.197. (British Museum (Natural History)/ Cornell University Press: London, 1979.) Hardback £5.95; paperback £2.95. Evolving: The Theory and Process of Organic Evolution. By F.J. Ayala and J.W. Valentine. Pp.452. (Benjamin/ Cummings: Menlo Park, California, 1979.) \$16.95. An Introduction to Evolutionary Genetics. By D.T. Parkin. Pp.220. (Edward Arnold: London, 1979.) Paperback £6.50. Evolution. Readings from Scientific American. Pp.135. (Freedman: San Francisco and Reading, UK, 1979.) Hardback £7; paperback £3.20. Ecological Genetics. By E.B. Ford. Pp.442. (Chapman and Hall: London, 1979.) Paperback £7.50.

THIS is a very mixed batch of books which vary greatly in the breadth and depth of their treatment of evolution and related subjects, in their intended readership and in their length. Some, having been written for the layman, assume no previous
On price, this text compares favourably with most of its competitors. It seems likely to achieve its author's hope of providing a broad general introduction to plant breeding as an intensely practical art.

Barbara Pickersgill is Lecturer in the Department of Agricultural Botany at the University of Reading, $U K$. knowledge of the subject, while others require at least a knowledge of elementary genetics and biology and are, therefore, of a more specialised interest.

Racle's book, though one of the shortest, attempts to cover the full range of evolutionary studies. Because it is intended for undergraduate non-science majors in American universities and colleges, it contains chapters on elementary geology, which is treated in an historical fashion, and Mendelian genetics. The chapter on population genetics is the least satisfactory not least because it is not at once made clear that the Hardy-Weinberg equilibrium applies only to a population of randomly mating individuals. Discussion of the sickle-cell polymorphism would also have been better done in this chapter rather than in the preceding one dealing with Mendelian genetics. The rest of the book treats the subject in an orthodox fashion and there are chapters on the evidence for evolution and natural selection, on the origin of life, phylogenetic divergence in the plant and animal kingdom, and two chapters on human evolution, though surprisingly, there is little about molecular evolution. The wide coverage of the subject in this short book, which is written in a pleasantly undemanding style, would make it suitable for use in schools.

Lenihan and Fletcher's book is the ninth volume in a series on Environment and Man and is intended for "practitioners and students in science, engineering, medicine, administration and planning"'. It is a rather odd and uneven book with few illustrations or diagrams. The chapters by Fletcher on "Evolution and the Natural Environment", by Ainsworth Harrison on 